\title{
Profile of Hospitalization for Sensitive Conditions Primary ORIGINAL
}

\section{Layza de Souza Chaves Deininger ${ }^{1}$, Kerle Dayana Tavares de Lucena ${ }^{2}$, Ericka Silva Holmes ${ }^{3}$,} Leidyanny Barbosa de Medeiros ${ }^{4}$, Barbara Maria Soares Pereira Wanderley ${ }^{5}$, Joacilda da Conceição Nunes ${ }^{6}$, Bárbara Meira de Oliveira ${ }^{7}$, Roseana Maria Barbosa Meira ${ }^{8}$, Cesar Cavalcanti da Silva ${ }^{9}$, Hemílio Fernandes Campos Coelho ${ }^{10}$, Eufrásio de Andrade Lima Neto ${ }^{10}$

\section{Abstract}

Objective: To present the profile of Hospitalization for Sensitive Conditions Primary the city of João Pessoa, Paraíba between 2008 and 2013.

Method: This is a descriptive, exploratory study with a quantitative approach, using secondary data, the Hospitalizations sensitive to primary care the city of João Pessoa, between 2008 and 2013, collected in December 2014.

Results: Sensitive Hospitalizations are more incidents at the extremes of age, accounting for about $16 \%$ of hospital costs.

Conclusion: The city's Primary Care should be evaluated to fulfill its role as a preferred gateway and care coordinator.

\section{Keywords}

Hospitalized; Primary Health Care; Access to Health Services.

\section{Introduction}

The Primary Health Care (PHC) was conceptualized for the first time in 1978 at the conference of Alma-Ata, characterized as the first level of contact of individuals, families and communities with the health system. It uses technologies and practical methods, scientifically proven to focus on the real health needs of the individual, family and community. It is considered crucial for the coordination and operation of the health care network, as it promotes the organization and rationalization of the use of resources, whether basic or specialized, in
1 Nurse. PhD student in Health and Decision Models - UFPB. Brazil.

2 Nurse. PhD in Health and Decision Models - UNCISAL. Brazil.

3 Nurse. Family Health Specialist. PhD student in Health and Decision Models - UFPB. Brazil.

4 Nurse. Family Health Specialist. Master in Health and Decision Models. UFPB. Brazil.

5 Nurse. Master student in Health and Decision Models. UFPB. Brazil.

6 Doctor, PhD in Child and Adolescent Medicine Course Coordinator, Faculty of Medical Sciences of Paraiba, Brazil.

7 Degree in Environmental Management by the Federal Institute of Education, Science and Technology of Paraíba, Brazil.

8 Pharmaceutical, Professor Master in Business Administration, Federal University of Paraíba, Brazil.

9 Nurse. PhD in Nursing USP Department of Nursing Federal University of Paraíba, Brazil.

10 Statistical Doctor. Department of Statistics Federal University of Paraíba, Brazil.

\section{Contact information:}

Ericka Silva Holmes.

Đ ericka_holmes@hotmail.com 
order to direct them to the promotion, maintenance and rehabilitation. [1]

In this sense, the PHC function properly, there will be instances of capacity reduction of preventable and indicative situations of poor care, the absence of disease prevention and health promotion actions; long intervals for home visits; difficulties in access to referral services, as well as an excess of hospitalizations for problems that can be solved at this level of attention as absence of disease prevention and health promotion actions; long intervals for home visits; difficulties in access to referral services, as well as an excess of hospitalizations for problems that can be solved at this level of attention. A health system with strong reference in the primary health care is more effective and satisfactory for the population, it has lower costs and is even fair in contexts of great social inequality. [2]

To strengthen PHC in Brazil in 1994, the Family Health Program was created (FHP) in order to replace the paradigms of the biomedical model for a universal health assistance, comprehensive and equitable, incorporating the principles guided by SUS. [2] In 1997, the PSF was organized as a management strategy and was renamed Health Strategy Family (HSF). [3]

The HSF is an expansion strategy, training and consolidation of primary care, since it favors the reorientation of the work process with high potential to deepen the principles, guidelines and rationale proposed by the PHC, but also to expand the solvability and impact on current health situation and enable a cost-effectiveness ratio. [2]

It is noteworthy that the PHC has significant importance in the functioning of the Unified Health System, this fact implies not only continued investments but also in detailed reviews of their level of performance and effectiveness, but also in the care of its principles and scope your goals. [4]

Following international trends, Brazil has consolidated in 2008, a list of health problems preventa- ble by action of PHC and adapted to the Brazilian epidemiological situation, in order to adjust the indicator Hospitalizations for Sensitive Conditions Primary (ICSAP) in order to analyze the health situation, guide decision-making and program health actions that improve and evaluate the effectiveness of PHC. [5-6]

For Nedel et al. [7], sensitive conditions PHC are health problems that should be treated by shares resulting from the first level of health care in this way in situations that there is lack of effective care and timely, you will need the use of specialized services and in many cases, hospitalization of patients.

The ICSAP may occur due to various factors, ranging from access and quality of care provided by the FHS, the determinants and social conditions of the territory and to the working process of the Family Health Teams.8 Thus, the analysis and search for explanations should help the manager in decision making in relation to improving the quality of health care services.

Please note that this study is justified by the need to verify the behavior of hospitalizations for causes sensitive to PHC and present the profile of such conditions, to assist professionals and managers in the decision-making process on a scientific basis, with a view to avoid unnecessary expenses, direct investments, prevent avoidable hospitalizations, and also support information to improve the quality of services provided to SUS users. Thus, it aimed to: present the profile of Hospitalization for Sensitive Conditions Primary the city of João Pessoa, Paraíba between 2008 and 2013.

\section{Method}

This is a descriptive, exploratory study with a quantitative approach. The data were secondary, collected from December 2014 considering the implementation of ICSAP National List in 2008. The information collected contemplated the years 2008-2013, through ordinance $N^{\circ} 221 / 2008$, which 
codifies ICSAP based on the 10th revision of the International Classification of Diseases (ICD-10). This study evaluated 19 groups of diagnoses of this list.

The ICSAP were selected from the Hospital Information System of the Unified Health System $(\mathrm{SIH}-$ SUS) available on the website of the Department of the Unified Health System (DATASUS), including Sensitive Hospitalizations variables to Primary Care Authorization Hospital admissions, frequency of hospitalizations, sex, age, year, payment and municipality (João Pessoa). The database tabulation procedure with the frequency of hospitalizations, occurred from the use of TabWin 3.7 application, available on the same site and exported to Microsoft Office Excel for building graphics.

Regarding the ethical aspects, the study was conducted with secondary health data in the public domain, not nominal and available basis for any ci- tizen in the DATASUS site, not resulting in any way, risk to the population studied, since globally were analyzed, and the use of information could benefit the users of SUS.

\section{Results and Discussions}

As figure 1 shows, most ICSAP presented few fluctuations between women and men, however, the vaccine-preventable diseases have prevalence four times higher for males, and there is no relationship between this cause of hospitalization and males, since vaccines are available in the public system for all citizens, regardless of sex. Infections of the kidney and urinary tract were exposed twice as frequent for women, this can cause is related to the anatomy of the female urinary system in which has its peculiarities.

Figure 1: Hospitalization for Sensitive Conditions Primary, second group of causes and sex, between 2008 and 2013, João Pessoa-PB, 2015.

19. Diseases related to prenatal and childbirth

18. Gastrointestinal ulcer

17. Inflammatory disease female pelvic organs 16. Infection of the skin and subcutaneous tissue

15. Infection in the kidney and urinary tract

14. Epilepsies

13. Diabetes mellitus

12. Cerebrovascular diseases

11. Cardiac insufficiency

10. Angina

9. Hypertension

8. Pulmonary diseases

7. Asthma

6. Bacterial pneumonias

5. Ear infections, nose and throat

4. Nutritional deficiencies

3. Anemia

2. Infectious gastroenteritis and complications

1. Preventable diseases / immunization / sensív

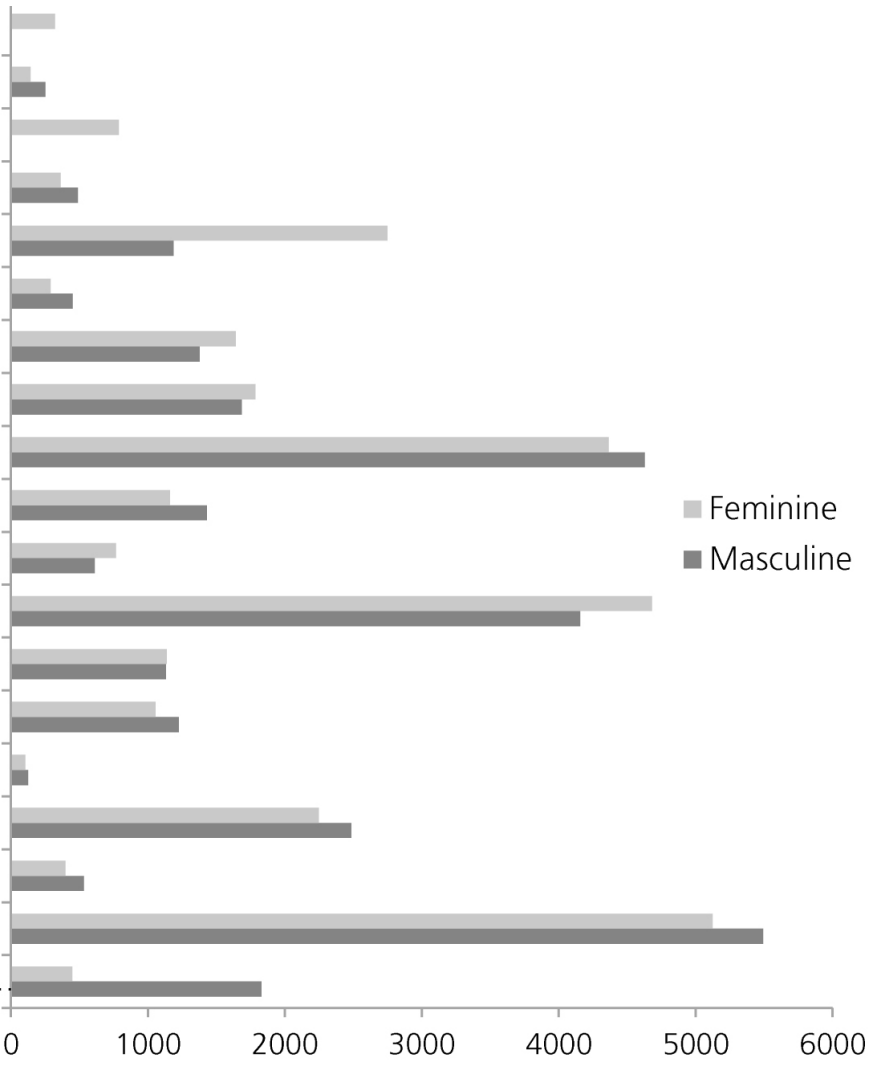

Source: DATASUS/SIH 
Nedel et al. [7] indicates an association between the risk of hospitalization for conditions Sensitive AP and structure, process and performance of primary care services, even states that preventive consultations (sporadic or not), immunization and day childcare consultations were associated in several studies to lower risk of these hospitalizations.

Preventable hospitalizations represent warning signal to managers and SUS health professionals. It is salutary to analyze them in order to identify gaps in care network, such as the lack of access, quality and resolution services that can lead to the maintenance of high rates of hospitalizations sensitive to PHS. [9] The analysis of ICSAP can support the observation adequacy of the epidemiological and sanitary context, and also serve as evidence-based decision making to aid tool and thereby assist the development of public actions and health policies based on the needs population. [3]

The figure 2 above is the analysis of the frequencies of ICSAP during the years 2008-2013, the three groups of causes, Gastroenteritis Infectious and complications (18\%), lung diseases (15\%) and heart failure (15.3\%) presented the highest incidence in all six years and between 19 ICSAP groups analyzed. In 2008 infectious gastroenteritis and complications were the group because of more incident hospitalization, however, this rate decreased continuously until 2013, but still remains high compared to other causes of hospitalization.
The pulmonary diseases in 2008 represented the second most frequent cause, there was a decrease in the frequency, but it appeared more frequent in 2013. Heart failure was the third most frequent cause in 2008 grew by 2010 and decreased frequency, representing the second most ICSAP incident in 2013.

There was a decrease these ICSAP, however, they still remained high, amounting to $48 \%$ of all hospitalizations sensitive to APS between 2008 and 2013, which points to the difficulty in providing effective and timely attention to these groups because in Primary Attention municipality, since services should prevent these diseases they needed specialized care and expensive. For Ferreira et al. [4] the occurrence of these admissions points to the need for a closer look at the management of the primary care network, with a view to adapting it to the needs of the population, these being defined from the diagnosis of the municipal health situation.

The figure 3 above is the prevalence by age group, the most frequent ICSAP in the years 2008-2013, so you can see the highest number of admissions in the age of extremes. In infectious gastroenteritis and complications, hospitalizations were more frequent in the early years of life until the early teens, increasing again after 65 years. The pulmonary diseases and heart failure diseases are similar in age groups with the highest number of hospitalization,

Figure 2: Hospitalizations for Sensitive Conditions Primary, second most prevalent causes between 2008 and 2013, João Pessoa-PB, 2015.

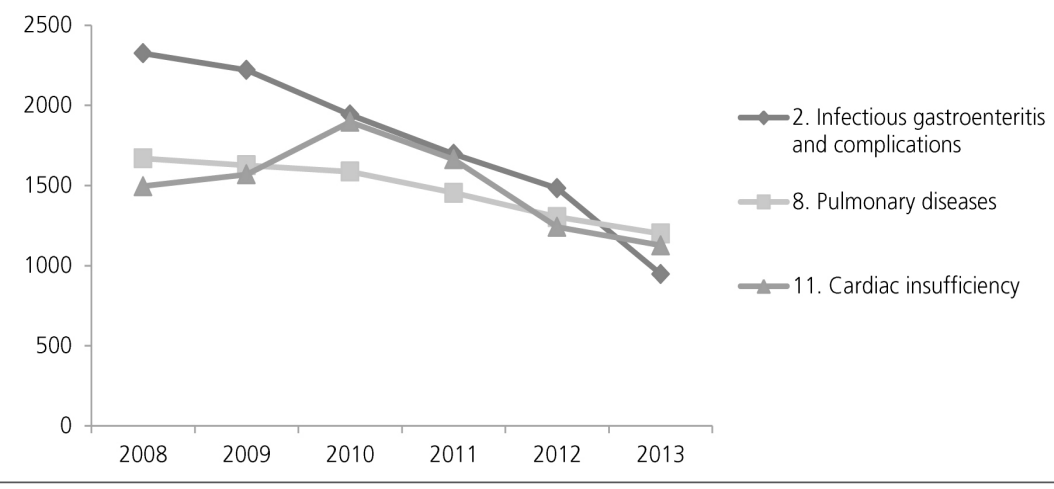

Source: DATASUS/SIH 
Figure 3: Hospitalization for Sensitive Conditions Primary for more common causes and age, between 2008 and 2013, João Pessoa-PB, 2015

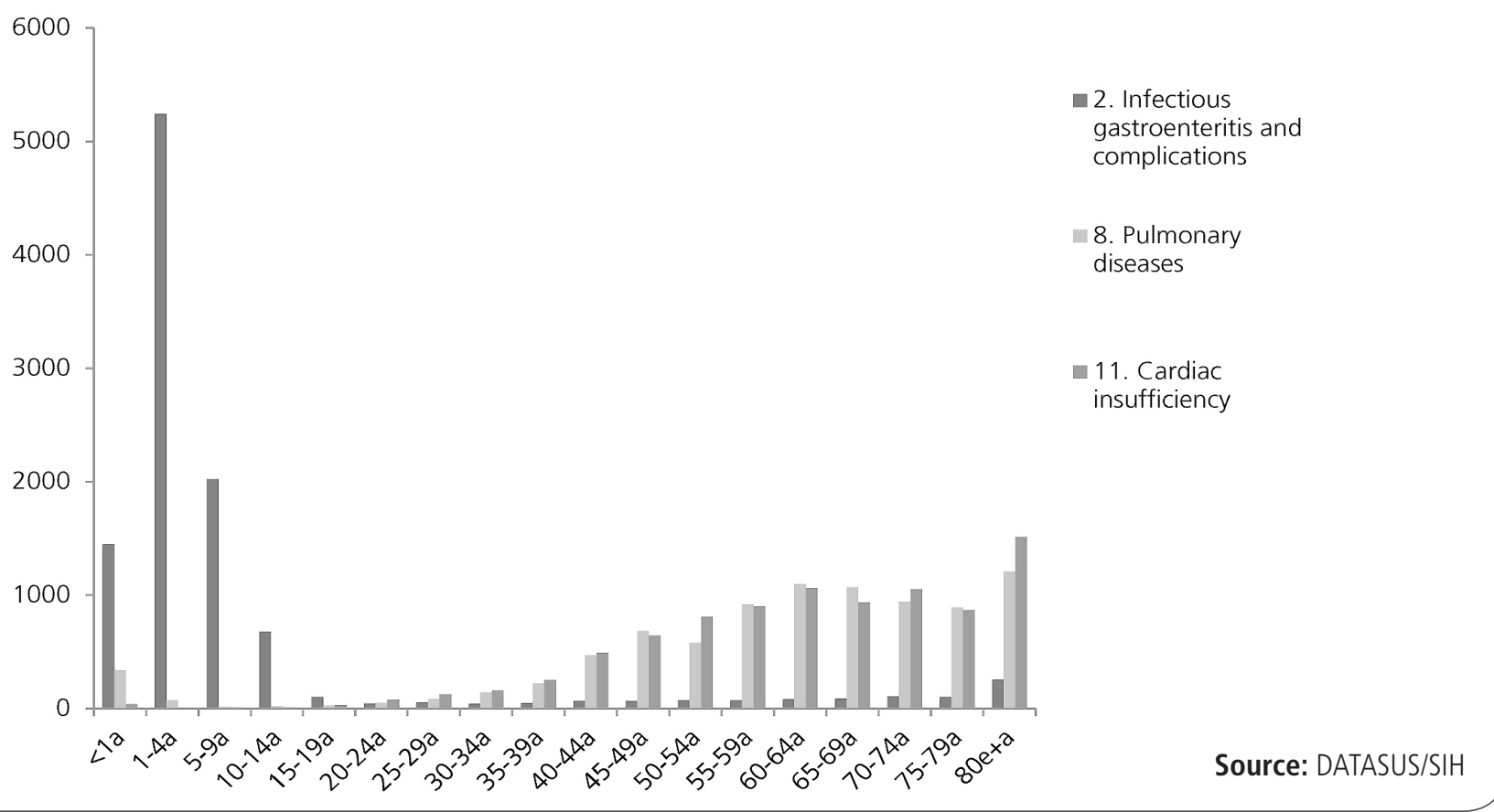

Figure 4: Hospitalizations sensitive to primary care second hospital expenses as a percentage, between 2008 and 2013, João Pessoa-PB, 2015.

Amount spent on ICSAP

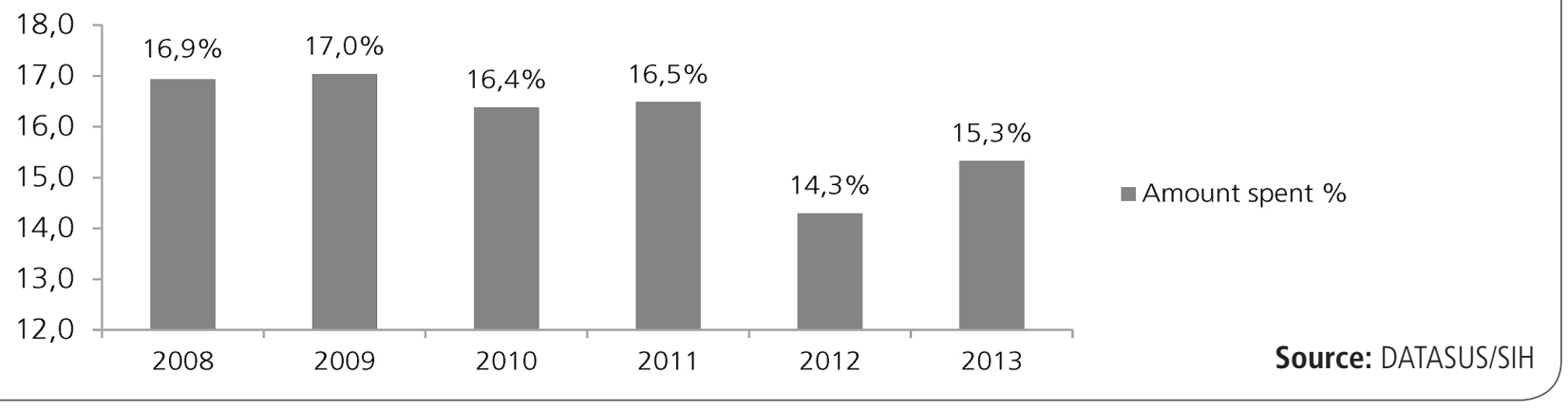

represented by people over 55 years with a significant increase in the elderly.

Corroborating Rehm et al. [8] in their study, hospitalization rates for ICSAP are more common in extremes of age, ie, the highest incidence is in children and the elderly. These admissions for infectious gastroenteritis and complications can be justified in terms of children and the elderly have fewer defenses against certain diseases and dehydrate faster, thus the need for intersectoral action PHC should be evaluated, as the investi- gation of possible links between the situation of water treatment and sewage in the territory and the grievances it. [4]

According to Rehem et al. [8] the pulonare diseases and Heart failure may be due to illness pattern of change, based on the aging of the population, being a result of expansion in life expectancy, from the epidemiological and demographic transitions.

Another possible explanation for the higher incidence of these ICSAP the extremes of age may 
Figure 5: Hospitalization for Sensitive Conditions Primary Care second groups cause most cost between 2008 and 2013, João Pessoa-PB, 2015.

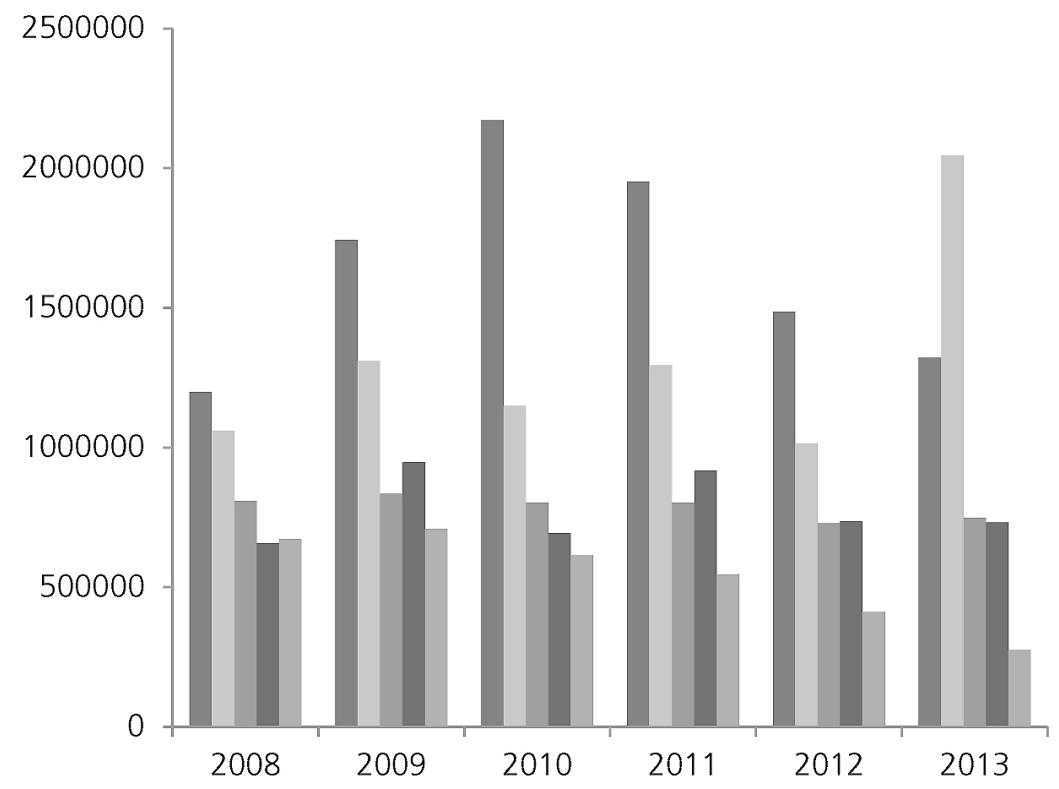

11. Cardiac insufficiency

10. Angina

8. Pulmonary diseases

घ 12. Cerebrovascular diseases

$\square$ 2. Infectious gastroenteritis and complications

Source: DATASUS/SIH

be that the elderly and children have less access to PHC services due to the high degree of dependence on responsible or companion, difficulties related to transportation, lack of physical conditions to get around to the units, especially the elderly, among other situations, worsening health status, and it needed hospital care. [8]

The figure 4 represents the amount spent on Hospitalizations sensitive to the actions of primary care in the six years studied, this amount is based on the total cost of hospital services and the total amount spent with ICSAP per year. So you can see that between the six years was spent a 16\% average of the amounts invested in hospital ( $R \$ 277.001 .175,00$ ), as well, during the six years analyzed were spent $\mathrm{R} \$ 44.381 .965,00$ with hospitalizations that could be avoided, and the investment used in the most deprived areas of health investment.

In a study by Ferreira et al. [4] spending ICSAP were $17 \%$ in a region of São Paulo, so the fact that ICSAP should be considered may reflect in a disruption of supply, solvability and access in primary health care, where the prevention and control of these diseases are directly related to the performan- ce of primary care services and the management of investments in health. a look based on careful studies for the best use of available resources in the health system and the design of its assistance empty, so that investments are more efficient, helping, therefore, the reduction of ICSAP should be performed.

The figure $\mathbf{5}$ above represents the five causes of admissions burdening more spending to the city of João Pessoa in all six years analyzed. Hospitalizations for heart failure caused higher expenses to the public coffers from 2008 to 2012, in 2013 the angina who was second, between 2008 and 2012, ranked first this year, with double spending compared to their 2012 data. Lung diseases represent the third cause of hospitalization, followed by cerebrovascular diseases and infectious gastroenteritis and complications. The three most frequent ICSAP were among the top five causes of hospitalizations requiring greater investment, including angina and cerebrovascular diseases, in many cases, require costly hospital procedures due to the use of equipment, specialized medical and hospital supplies. 
Heart failure was responsible for about $22 \%$ of spending ICSAP, angina by about $18 \%$, pulmonares diseases and cerebrovascular diseases by about $11 \%$ each, infectious gastroenteritis by $7 \%$, therefore, the sum these diseases are responsible for $68 \%$ of spending ICSAP in the city of João Pessoa.

Given the above, it is imperative to point out that essential improvements must be made in the APS, with financial and structural investments and its main attributes such as longitudinality care and comprehensive care, improving access and quality of services, effective care coordination, consideration of the individual and the family and community and the establishment of links between the services and the people with the responsibility of care, these features may help in decreasing the occurrence of ICSAP. [4]

\section{Conclusions}

The study points to a similar distribution of ICSAP between the sexes, indicating no significant overlap. Regarding the age group with the highest number of admissions, it was found that the extremes of age showed higher frequency. During the six years examined, an expense of about $16 \%$ was observed for hospital investments, hospitalizations for preventable causes, with the highest hospitalization costs related to heart failure, angina, Pulmonary Diseases, Cerebrovascular diseases and gastroenteritis Infectious and its complications respectively.

Thus, these expenses that could be avoided, can have its reason in the fragility linked to the lack of resolution of Primary should assume the role of coordinator of care to users. Large costs ICSAP indicate problems of access and performance of health services, and to analyze and find solutions to assist the manager in decision making and the development of effective public policies that address the health needs of the population.
Hospitalizations for conditions sensitive to primary care makes it possible to compare the performance of various health services, and raise research on inequalities in access between regions and communities, assisting in strengthening primary care, main gateway to the National Health System.

However, this type of study has limitations inherent in studies using secondary data such as inability to control or guarantee the quality of data. However, it noted the importance of the public availability of such data and its use by researchers and managers to assist in the planning process of health actions.

\section{References}

1. Starfield B. Primary care: an increasingly important contributor to effectiveness, equity, and efficiency of health services. SESPAS report 2012. Gaceta Sanitária. [Internet] 2012. [acess 25 ago 2015]; 26: 20-6. 2012. Available from: www.ncbi.nlm.nih. gov/pubmed/22265645

2. Brasil. Conselho Nacional de Secretários de Saúde. Atenção Primária e Promoção da Saúde: para entender a gestão do SUS. 2011, 3, Brasília : CONASS.

3. Deininger, L.S.C.; Silva, C. C.; Lucena, K. D. T.; Pereira, J.R.; Lima Neto, E. A. Internações por condições sensíveis à atenção primária: revisão integrativa. Revista de Enfermagem da UFPE On line. [Internet] 2015; [acess 16 fev 2016]; 9(1):228-36. Available from: www.revista.ufpe.br\%2Frevistaenfermagem \%2Findex. php\%2Frevista\%2Farticle\%2Fdownload\%2F7142\%2F11238\&e i=8EbVdydMYmZwgSN15CAAQ\&usg=AFQjCNFmLaQaz4qTute kE8VyDBiwse z1Q\&bvm=bv.96952980,d.Y2I

4. Ferreira, J.B.B.; Borges, M.J.G.; Santos, L.L.; Foster, A.C. Internações por condições sensíveis à atenção primária à saúde em uma região de saúde paulista, 2008 a 2010*. Epidemiologia e Serviços de Saúde. 2014; 23(1):45-56.

5. Brasil. Ministério da Saúde. Portaria $n^{\circ}$ 221, de 17 de abril de 2008. Publica a lista brasileira de internações por condições sensíveis à atenção primária. Diário Oficial da União, Brasília, p.70, 18 abril 2008, Seção 1. 
6. Alfradique, M.E.; Bonolo, P.F.; Dourado, I.; Lima-Costa, M.F.; Macinko, J.; Mendonça, C.S.; et al. Internações por condições sensíveis à atenção primária: a construção da lista brasileira como ferramenta para medir o desempenho do sistema de saúde (Projeto ICSAP - Brasil). Caderno de Saúde Pública. [Internet] 2009; [acess 20 ago 2015]; 25(6):1337-49. Available from: http://www.scielo.br/scielo.php?script=sci arttext\&pid=S0102311X2009000600016

7. Nedel, F.B.; Facchini, L.A.; Martín, M.; Navarro, A. Características da atenção básica associadas ao risco de internar por condições sensíveis à atenção primária: revisão sistemática da literatura. Epidemiologia e Serviços de Saúde, Brasília. 2010; 19(1): 61-75, jan-mar.

8. Rehem, T.C.M.; Oliveira, M.R.F.; Amaral, T.C.L.; Ciosak, S.I.; Egry, E.Y. Internações por Condições Sensíveis à Atenção Primária em uma metrópole brasileira. Revista da Escola de Enfermagem da USP. 2013; 47(4): 884-90.

9. Boing, A.F.; Vicenzi, R.B.; Magajewski, F.; Boing, A.C.; MorettiPires, R.O.; Peres, K.G.; et al. Redução das Internações por Condições Sensíveis à Atenção Primária no Brasil entre 19982009. Revista de Saúde Pública. 2012; 46(2): 359-66.

Publish in International Archives of Medicine

International Archives of Medicine is an open access journal publishing articles encompassing all aspects of medical science and clinical practice. IAM is considered a megajournal with independent sections on all areas of medicine. IAM is a really international journal with authors and board members from all around the world. The journal is widely indexed and classified Q1 in category Medicine. 